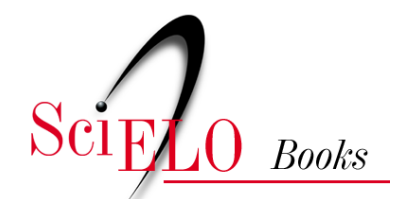

\title{
Capítulo 1 - 0 campo teórico da discussão entre democracia e desigualdade
}

\author{
Ivan Filipe de Almeida Lopes Fernandes
}

\section{SciELO Books / SciELO Livros / SciELO Libros}

FERNANDES, I.F.A.L. O campo teórico da discussão entre democracia e desigualdade. In: A democracia reduz a desigualdade econômica? Um estudo sobre as possibilidades de construção de uma sociedade mais igual por meio da democracia [online]. São Bernardo do Campo, SP: Editora UFABC, 2017, pp. 21-66. ISBN: 978-85-68576-79-3. https://doi.org/10.7476/9788568576793.0002.

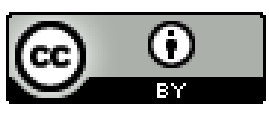

All the contents of this work, except where otherwise noted, is licensed under a Creative Commons Attribution 4.0 International license.

Todo o conteúdo deste trabalho, exceto quando houver ressalva, é publicado sob a licença Creative Commons Atribição 4.0.

Todo el contenido de esta obra, excepto donde se indique lo contrario, está bajo licencia de la licencia $\underline{\text { Creative }}$ Commons Reconocimento 4.0. 
Capítulo 1

\section{0 campo teórico da discussão entre democracia e desigualdade}

A promoção da democracia pelo mundo tornou-se uma característica marcante da agenda política internacional por vários motivos, destacando-se a suposta propensão da democracia em reduzir as disparidades econômicas entre os indivíduos de uma mesma comunidade política (TIMMONS, 2010). A noção de que a equidade política reduz as disparidades econômicas está profundamente enraizada nas ciências sociais (BOLLEN; JACKMAN, 1985). Desta forma, dada a proliferação de governos representativos e a grande disparidade de renda existente entre e dentro dos países, a relação entre democracia e desigualdade econômica tem significado prático e acadêmico imenso.

Boa parte das teorias em que as eleições democráticas importam baseia-se na suposição de que as democracias são qualitativamente diferentes de não democracias, especialmente no que se refere à distribuição e redistribuição de recursos e status entre os indivíduos. Esta conexão entre instituições políticas e redistribuição tem suas raízes no pensamento clássico de Aristóteles (2005), Maquiavel (1979) e John Stuart Mill (1862). Para o pensador grego em A política (2005): "nas democracias os pobres possuem maior poder soberano que os 
homens de propriedade: pois eles são mais numerosos e a decisão da maioria prevalece" (MILL, 1861; MAQUIAVEL, 1979; ARISTOTELES, 2005).

O ponto de partida desta pesquisa é discutir se a democracia, por intermédio da criação de condições políticas iguais, contribui para a edificação de maior equidade econômica. De fato, durante o século XIX, a equidade política e a equidade econômica conectavam-se tal qual um silogismo social. O sufrágio universal combinado com a regra majoritária concederia poder político para a maioria e devido ao fato de que a maioria é sempre pobre, ela adquiriria as condições políticas necessárias para confiscar a riqueza dos ricos e compartilhá-la com todos na sociedade, incluindo aqui o próprio fim do direito à propriedade privada (PRZEWORSKI, 2010).

Na visão de Gerring, Thacker e Alfaro (2012), a hipótese de que as instituições democráticas promovem uma dinâmica política favorável às necessidades e interesses dos menos favorecidos tornou-se um axioma teórico fundamental na comparação entre democracias e ditaduras. Gerhard Lenski (1966) afirma inclusive que a retórica da democracia se baseia na ideia de que existe uma redistribuição de poder em favor dos desfavorecidos, a maioria em qualquer sociedade. A ideologia democrática legitimaria a redistribuição do poder em favor dessa maioria desfavorecida. E com este aumento da igualdade política, medidas em favor de uma maior igualdade social e uma distribuição mais igualitária de bens seriam inevitavelmente introduzidas.

Adam Przeworski (2010) entende que esta previsão foi um tema central do debate e dos conflitos políticos em torno da expansão do sufrágio universal e da consolidação da democracia como forma de governo nos países ocidentais. Tal conexão entre a expansão democrática por meio do sufrágio universal e o fim da propriedade fora levantada e debatida tanto 
por intelectuais conservadores quanto por socialistas. Grupos conservadores se opuseram à expansão dos direitos políticos ao longo da história, temendo as consequências distributivas do novo regime que poderiam minar a favorável posição econômica dos privilegiados (BOLLEN; JACKMAN, 1985)

$\mathrm{Na}$ visão do economista David Ricardo para evitar a ameaça democrática à liberdade, a extensão do sufrágio deveria estar limitada apenas para aqueles cidadãos que não possuem interesse em eliminar o direito à propriedade privada. Thomas Macaulay em seu discurso sobre o movimento cartista em 1842 vislumbrou a expansão do sufrágio como "o fim da propriedade e assim de toda a civilização" (PRZEWORSKI, 2011). Na outra ponta do espectro ideológico, Karl Marx (1972) expressou forte convicção de que a propriedade privada e o sufrágio universal eram inerentemente incompatíveis, conforme explicitado em estudo sobre os conflitos de classe na França entre 1848 e 1850:

A ampla contradição desta Constituição consiste, porém, no seguinte: As classes cuja escravidão social deve eternizar: proletariado, camponeses, pequenos burgueses, ela coloca-as na posse do poder político por meio do sufrágio universal. E a classe cujo velho poder social sanciona, a burguesia, ela retira-lhe as garantias políticas desse poder. Comprime a sua dominação política em condições democráticas que a todo o momento favorecem a vitória das classes inimigas e põem em causa os próprios fundamentos da sociedade burguesa. A umas, exige que não avancem da emancipação política para a social, às outras, que não retrocedam da restauração social para a política. (KARL MARX, 1849) ${ }^{2}$.

${ }^{2}$ As lutas de classes em França de 1848 a 1850, Parte II, de junho de 1848 a 13 de junho de 1849 (MARX, 1972). 
$\mathrm{Na}$ visão do intelectual socialista, a democracia inevitavelmente abriria uma enorme fronte de conflito entre as classes sociais ao deslocar o poder político das elites aristocráticas para a maioria. Assim podemos concluir que às vésperas da revolução democrática do século $\mathrm{XX}$, em todos os espectros do debate político, existia uma forte percepção de que as relações entre democracia, capitalismo e propriedade privada, e, sobretudo, as relações entre democracia e desigualdade econômica seriam inerentemente instáveis.

A crença na relação negativa entre democracia e desigualdade tem sido uma das principais razões pelas quais os movimentos políticos reformistas têm procurado garantir os direitos políticos para os grupos que estão fora da cidadania ${ }^{3}$. Lipset (1959) argumentou que as estruturas políticas democráticas promovem eleições que servem como a expressão da luta de classe democrática, pois os cidadãos tendem a votar em partidos que concorrem primordialmente pela representação dos interesses das classes médias e trabalhadoras. A extensão do sufrágio àqueles que não possuíam propriedades e/ou riqueza tenderia, portanto, a aumentar a competição política em sociedades industriais, movendo o debate e a disputa para a esquerda do espectro político (LENSKI, 1966; GRADSTEIN; MILANOVIC, 2004).

Outros têm argumentado que a democracia aumenta as oportunidades de participação, permitindo que os pobres

\footnotetext{
3 O impacto negativo da democracia sobre a desigualdade econômica é definido do ponto de vista estatístico, o que significa que a democracia e a desigualdade variam inversamente: isto é, quanto maior uma, menor a outra. Os termos impactos positivos e negativos serão sempre utilizados segundo este prisma de covariação estatística e nunca segundo um ponto de vista normativo, no qual o efeito da democracia seria bom (positivo) quando reduzisse a desigualdade econômica.
} 
possam exigir uma redistribuição de renda mais equitativa. Isto porque com a expansão do sufrágio, os líderes democráticos em busca da reeleição de seu grupo no poder são responsabilizados perante os eleitores e sintonizam-se cada vez mais com as suas necessidades, facilitando a eleição de representantes de partidos trabalhistas ou sociais democráticos (CHAN, 1997). Diante disso, governos democráticos tornar-se-iam mais inclinados a ajudar as classes pobres e médias por meio da adoção de políticas redistributivas como gastos com bem-estar social, políticas tributárias progressivas, fixação de salário mínimo e preços subsidiados, entre outros. (RODRIK, 1998a).

Os efeitos dos regimes autoritários em fomentar o crescimento da desigualdade também explicariam parte dos benefícios trazidos pela democracia. Os líderes autoritários ao ser responsabilizados perante apenas uma minoria rica e podero$\mathrm{sa}^{4}$, tendem a adotar políticas públicas que beneficiem estritamente essa minoria, mantendo ou aumentando a desigualdade econômica. E a própria análise dos benefícios da competição política democrática é realizada em comparação com os resultados produzidos vis-à-vis aos outputs dos regimes não democráticos, sendo estes tomados com um conjunto definido pela negação - a ausência de competição política democrática ${ }^{5}$; e não por alguma característica semelhante a todos ${ }^{6}$.

\footnotetext{
${ }^{4}$ Não importando ao argumento se os detentores do poder são ricos antes de assumirem a posição de autoridade ou se amealham mais recursos econômicos em movimento posterior à obtenção do poder político.

5 Como esclarecemos mais a frente, assumimos a definição minimalista de democracia adotada por Przeworski, Alvarez, Cheibub e Limongi (2000), na qual é o regime em que partidos competem pelo poder político em eleições abertas, livres e justas, com incerteza ex-ante e certeza ex-post acerca dos resultados eleitorais.

${ }^{6}$ Um tema que não é debatido nessa pesquisa, mas que é de fundamental importância para análise da relação entre regime político e desigualdade é o estudo
} 
Especificamente, se argumenta que regimes autoritários conseguem com mais facilidade adotar políticas que beneficiem uma minoria à custa da maioria excluída da comunidade política, devido ao fato que não existe nenhum mecanismo político a partir do qual seja possível responsabilizar o poder político à maioria. Evans (1995) e Kaufman (1979), por exemplo, sugerem que regimes autoritários tem mais liberdade em colaborar com corporações sediadas no exterior para promover um setor moderno pequeno e bem remunerado à custa do setor econômico tradicional, maior e mais pobre. Tais padrões implicam que os regimes não democráticos tenderiam a gerar mais desigualdade em favor das elites econômicas e em detrimento dos camponeses e trabalhadores. Este resultado parece típico se olharmos as consequências distributivas de regimes autoritários modernizantes como os encontrados durante o período militar brasileiro e chileno ou mesmo o regime iraniano do Xá Reza Pahlevi.

Neste capítulo apresentamos as diferentes contribuições da literatura em economia política comparada sobre a relação entre democracia e desigualdade. Na primeira seção organizamos a literatura segundo os diferentes mecanismos a partir dos quais a democracia impacta negativamente na desigualdade econômica. A seguir realizamos um breve balanço da literatura empírica, na qual até agora não há consenso se a relação é positiva, negativa ou nula.

de como diferentes institucionalidades e tipos de lideranças autoritárias afetam a desigualdade econômica de uma determinada comunidade política. Em nossa pesquisa assumimos que ditadura é todo e qualquer regime que não é democrático, mas não examinamos os efeitos que diferentes configurações institucionais autoritárias possuem sobre a desigualdade e qual é a performance da democracia em comparação a esses diferentes tipos de regimes ditatoriais. Para uma análise sofisticada das variações institucionais entre os regimes autoritários ver (SVOLIK, 2012). 
$\mathrm{Na}$ terceira, quarta seção apresentamos sucintamente a literatura sobre alguns determinantes da desigualdade econômica que são potenciais fatores de confusão na relação entre democracia e desigualdade, tais como o próprio processo de desenvolvimento econômico e tecnológico. Além disso, uma influência relevante é o papel da expansão das relações de mercado, acentuadas ainda mais no pós Guerra Fria com a crescente globalização econômica e a aceleração dos fluxos internacionais de comércio e finanças. Isto porque existe uma associação forte entre a expansão dos sistemas democráticos e a expansão de mercados e, de acordo com análises empíricas recentes, o livre mercado tem efeito direto no aumento da desigualdade econômica, pois os indivíduos são dotados de diferentes conjuntos de bens, habilidades e recursos, remunerados a taxas distintas (PRZEWORSKI, 2010; PIKETTY, 2014).

$\mathrm{Na}$ quinta seção tratamos da potencial relação causal inversa entre democracia e desigualdade. Após um vasto esforço de se entender os efeitos do desenvolvimento econômico sobre os processos de democratização, a literatura comparada se interessou por como a distribuição de recursos dentro de uma dada sociedade pode afetar as possibilidades de um regime autoritário adotar instituições democráticas e de um regime democrático reproduzir-se ao longo do tempo (ANSELL; SAMUELS, 2014). Por fim, concluímos o capítulo e introduzimos os temas do próximo.

\subsection{0 debate sobre a relação entre democracia e desigualdade}

A literatura sobre efeitos da democracia na mitigação do problema da desigualdade econômica formulou quatro mecanismos gerais por meio dos quais os regimes democráticos 
exercem uma pressão em direção a uma maior equidade econômica (TIMMONS, 2010; GERRING; THACKER; ALFARO, 2012).

O primeiro mecanismo é baseado na relação entre os sistemas de tributação e transferências de renda que decorre de postulações teóricas tomadas à luz do teorema do eleitor mediano de Harold Hotelling e Anthony Downs. No texto clássico de Meltzer e Richard (1981) o ponto de equilíbrio do tamanho do governo é modelado como consequência da regra majoritária e da distribuição de produtividade na economia ${ }^{7}$ (HOTELLING, 1929; DOWNS, 1957). A extensão dos direitos de sufrágio, a posição do eleitor mediano, cuja preferência determina as políticas governamentais, é deslocada para baixo na distribuição de renda. Em condições de sufrágio universal, o eleitor mediano tende a ter renda idêntica à renda mediana. E como está é inferior à renda média, ele favorece uma política tributária distributiva e progressiva, transferindo renda das elites para os menos favorecidos.

Os modelos de economia política que partem do arcabouço de Meltzer e Richard invariavelmente afirmam que quanto maior a desigualdade econômica - isto é: uma distância maior entre as rendas médias e mediana - maior a taxa de redistribuição por meio da ação eleitoral e política do governo democrático. A teoria é sintetizada na ideia de quanto maior for a distância entre a renda do eleitor mediano e a renda média da população, maior será a tendência de o governo redistribuir renda do topo para a base, reduzindo o escopo

\footnotetext{
7 Os modelos do eleitor mediano sobre a redistribuição (ROMER, 1975; ROBERTS, 1977; MELTZER; RICHARD, 1981) são o ponto de partida para grande parte da discussão sobre a economia política do Estado de Bem-Estar Social.
} 
da desigualdade econômica ${ }^{8}$. De forma simplificada, como as democracias levam às urnas uma parcela majoritária de indivíduos que possuem renda inferior à média, essa maioria, atuando coletivamente, força o governo a redistribuir renda da elite para as massas.

O modelo redistributivo de Meltzer e Richard assume que o governo tributa uma porcentagem específica e uniforme da renda dos indivíduos e, a partir da arrecadação obtida, distribui um benefício universal e de igual valor para todos. Assim são criados incentivos para a redistribuição, quaisquer que sejam as regras de votação que concentrem votos abaixo da renda média, uma vez que a distribuição de renda é quase sempre desviada para a esquerda. E como nos modelos redistributivos a distribuição da renda bruta ${ }^{9}$ é exógena ao sistema político, a redução da desigualdade é simplesmente assumida como o estreitamento da distância entre a renda individual e a renda média para todos os grupos de renda.

Bergh (2005) critica essa forte suposição do modelo redistributivo, uma vez que ela implica que as políticas públicas redistributivas não afetam a oferta de trabalho. Caso exista um efeito das políticas redistributivas sobre o trabalho ofertado, é necessário levar em conta o impacto posterior da política

\footnotetext{
${ }^{8}$ Meltzer e Richard (1981) usam a parcela de renda distribuída pelo governo em dinheiro e em serviços como uma medida do tamanho relativo do governo e desenvolvem uma teoria no qual o tamanho do governo é definido por escolhas racionais de indivíduos maximizadores de utilidade que são completamente informados sobre o presente estado da economia e das consequências da taxação e da redistribuição de renda (MELTZER; RICHARD, 1981).

9 A distribuição de renda bruta é definida pela renda dos indivíduos antes de impostos e transferências: a distribuição da renda obtida pelos indivíduos em situação de mercado. Já a distribuição de renda líquida é definida pela renda dos indivíduos após a tributação e transferências públicas.
} 
redistributiva na distribuição de renda pré-tributação - a renda bruta, tornando-a endógena ao modelo redistributivo. $\mathrm{Na}$ visão de Bergh, os diferentes grupos da sociedade devem responder de maneira distinta à oferta de benefícios públicos, o que pode ocasionar tanto aumento quanto diminuição da desigualdade bruta. Por exemplo, indivíduos mais jovens tendem a reduzir a sua oferta de trabalho se existem recursos públicos para serem investidos em sua própria educação, enquanto mulheres tendem a reduzi-la para dedicar mais tempo à educação e criação de seus filhos, e, por fim, idosos tendem a se retirar mais facilmente do mercado por razões de saúde (NICAISE, 1998; BERGH, 2005).

Boix (2010) argumenta na mesma linha ao analisar que na escolha de políticas públicas que beneficiam o eleitor mediano, é necessário levar em conta não apenas o impacto direto da ação pública na renda líquida desse indivíduo (BOIX, 2010). Um arcabouço regulatório molda a renda bruta de todos os indivíduos. Desta forma, ao se calcular as consequências de determinado arcabouço institucional é necessário o cálculo da mudança final da renda do eleitor mediano, levando em conta os efeitos da tributação, da oferta de trabalho e os custos da participação política ${ }^{10}$. Robinson (2009) por sua vez sublinha que não existe a possibilidade de uma distribuição de renda de

\footnotetext{
10 Outra possível consequência é o impacto de gastos com educação na capacidade de engrandecimento do capital humano individual. Isto porque se a distribuição de capital humano for desigual, o aumento do gasto público em educação tende a reduzir essa desigualdade, endogenizando, por meio de outro mecanismo, a distribuição de renda pré-tributação (BERGH, 2005). Usando dados sobre gastos governamentais em educação, Sylwester (2002) mostrou que países que destinaram maior parte do seu PIB para a educação pública experienciaram menor desigualdade nos anos subsequentes (SYLWESTER, 2002; BERGH, 2005).
} 
mercado tal como ela fosse livre de quaisquer influências do mundo da política. A própria ideia de mercado é em parte uma construção política (PRZEWORSKI, 2003). Para existir o livre mercado capitalista é necessária a construção institucional dos direitos de propriedade e das próprias esferas de mercado, que só são garantidos a partir da ação política do próprio estado, pois é o sistema político quem determina a natureza destes direitos de propriedade e o quão livre estão os agentes econômicos para operarem dentro de determinadas estruturas de trocas.

Não obstante, mesmo que os regimes políticos reais não se encaixem perfeitamente na estrutura teórica do modelo do eleitor mediano, as conclusões gerais do modelo implicam que de alguma forma as democracias devem apresentar sistematicamente um nível inferior de desigualdade do que as não democracias, ainda que a relação entre a diferença da renda do eleitor mediano com a renda média e a taxa de redistribuição não seja perfeitamente monotônica e nem as predições do modelo sejam passiveis de aceitação teórico-formal (ACEMOGLU; ROBINSON, 2006).

Ademais, estudos quantitativos recentes mostram que as democracias tendem a produzir maior quantidade de bens e serviços públicos e mais redistribuição de renda que ditaduras. (AVELINO; BROWN; HUNTER, 2005; ROSS, 2006; GERRING; THACKER; ALFARO, 2012). Estudos históricos também mostram uma correlação entre a extensão do sufrágio e o tamanho do governo nos EUA, Europa e América Latina (KRISTOV; LINDERT; MCCLELLAND, 1992; LINDERT, 1994; GOUVEIA; MASIA, 1998). Bueno de Mesquita et al. (2005) são incisivos ao elaborarem um modelo sobre a sobrevivência das lideranças políticas, no qual quanto maior for a 
participação para a escolha do governo (selectorate) e a base de apoio deste governo (winning coalition), maiores serão os incentivos para a produção de bens públicos ${ }^{11}$.

O segundo mecanismo é a competição política e o papel desempenhado pelo voto retrospectivo e prospectivo, que sublinha a conexão eleitoral entre o eleitor e as lideranças políticas e a responsividade engendrada pelo ordenamento político democrático (KEY, 1949). O arcabouço básico do mecanismo de competição política se fundamenta no argumento de que quanto mais os líderes políticos competem entre si e em grupos organizados pelo apoio dos cidadãos, mais serviços são produzidos pelo setor público para dado nível de arrecadação do governo. E devido ao fato que a democracia está intimamente relacionada com a existência de competição política, a melhora dos serviços prestados pelo governo é estimulada.

$\mathrm{Na}$ visão de Gerring, Thacker e Alfaro (2012), como a miséria generalizada é impopular, líderes democraticamente eleitos são mais cuidadosos com problemas referentes ao desenvolvimento humano. Um exemplo disto é a constatação de Sen e Dreze (1989) de que até hoje nunca foram registradas crises humanitárias em regimes democráticos. Sen (1983; 1999) argumenta que em democracias, por meio do processo eleitoral, os pobres podem penalizar os governos que permitem o desenvolvimento de crises humanitárias:

A fome mata milhões de pessoas em diferentes países do mundo, mas nunca mata os governantes... se não houver eleições, sem partidos de oposição, sem espaço

\footnotetext{
11 Outra forma de interpretação dos resultados de Bueno de Mesquita et al. (2005) sugere que os governos democráticos têm uma gama mais ampla de apoiadores para atender, que os induz à produção de mais bens públicos em comparação a bens privados.
} 
para críticas públicas não censuradas, então aqueles que possuem autoridades não irão sofrer as consequências políticas no fracasso em evitar crises de fome. As democracias, por outro lado, estenderiam os efeitos negativos da fome para os grupos dominantes e os líderes políticos. (SEN, 1999) ${ }^{12}$.

Valdimer O. Key (1949), por sua vez, conecta explicitamente a relação entre democracia e desigualdade à competição política. Ao analisar o sistema de partido único dos estados do sul dos EUA, ele conclui que a organização política unipartidária impede o debate organizado sobre temas e, ao contrário, leva o debate político a uma disputa de personalidades. As instituições democráticas seriam fundamentais ao darem origem a competição política organizada. A falta de concorrência sustentada entre dois grupos políticos claramente definidos tornaria o governo mais suscetível a pressões individuais e favoritismo, impedindo o debate sobre temas abrangentes. Isto posto, Key conclui que os sistemas de partido único têm um viés pró-status quo que beneficia as elites privilegiadas em detrimento dos pobres. Sem a competição política entre partidos organizados, os pobres não possuiriam nenhum mecanismo que possibilitasse a sua participação política efetiva nas decisões do Estado.

Além disso, com uma distribuição mais equitativa de poder, a democracia dá mais espaço para que os sindicatos de trabalhadores e partidos políticos representem as classes sociais fora do restrito círculo das elites, assim como estimula a criação de políticas públicas para competir pelo voto das bases

12 Todas as citações de trabalhos em língua estrangeira foram traduzidas livremente. 
sociais desses sindicatos e de partidos não elitizados. Quanto mais organizados e vitais estes grupos forem, maior será o seu sucesso na busca por influência no processo decisório partidário. $\mathrm{E}$ caso os grupos de menor renda se beneficiem mais das atividades governamentais, especialmente da educação pública, a democracia tenderá a reduzir a dispersão de capital humano na sociedade, causando, no longo prazo, a queda da desigualdade (SAINT-PAUL; VERDIER, 1993).

Por fim, Sen (1999) argumenta que a democracia permite que um maior fluxo de informação seja transmitido das áreas mais pobres e remotas para o governo central devido ao trabalho da livre imprensa e do uso e divulgação estratégica de informações por aqueles que buscam ocupar e competem pelo centro do sistema político. Assim, quando existe a possibilidade de surgimento de uma crise falimentar, a mídia e opositores têm incentivos políticos e institucionais para trazer à tona fatos que sejam negativos para o governo e que usualmente seriam censurados em ditaduras.

O terceiro mecanismo que indica a tendência da democracia ser mais efetiva na redução da desigualdade econômica é a presença de uma sociedade civil mais institucionalizada e desenvolvida, uma vez que os direitos políticos e os direitos civis são altamente correlacionados. A existência de direitos civis estimula, no decorrer do tempo, a criação de uma rede densa de associações voluntárias que prestam serviços aos desfavorecidos, muitas vezes em conjunção com entidades governamentais, que também tendem a influenciar as atividades legislativas por meio de pressão política e atividades de lobby (GERRING; THACKER; ALFARO, 2012). Para Simon Kuznets (1955):

O crescimento do poder político dos grupos urbanos de menor renda leva a uma variedade de leis de proteção e 
apoio, muitas das quais buscam combater os piores efeitos da rápida industrialização e urbanização e apoiar as reivindicações das grandes massas para uma participação maior na renda crescente do país. (KUZNETS, 1955).

A provisão dos benefícios oriundos dos serviços do Estado de bem-estar social demandados por essas organizações representaria um importante meio pelo qual o governo poderia influenciar a desigualdade (RUEDA, 2008). Esses serviços, além de redistribuírem riqueza para os pobres, também minimizam os riscos do mercado de trabalho (MOENE; WALLERSTEIN, 2003). Assim, existem duas formas nas quais os gastos do governo podem afetar a desigualdade. Primeiro, reduzindo os riscos dos trabalhadores, pois os programas de bem-estar têm como consequência imediata reduzir a dependência das pessoas à participação no mercado de trabalho como fonte de riqueza (ESPING-ANDERSEN, 1991). Segundo, Iversen e Cusack (2000) apontam que os serviços providos pelo governo reduzem a desigualdade no acesso à educação $\mathrm{e}$ saúde, além de ampliarem o escopo do emprego público, que também pode ser utilizado como mecanismo de redução da variação salarial.

Por fim, o quarto e último mecanismo enfatiza explicitamente as consequências da democracia na regulação do mercado de trabalho. Como notado por Schumpeter (2013), a democracia reduz o custo de participação política do trabalho organizado, permitindo que obtenha uma posição mais privilegiada no processo político. Rodrik (1998a) revisitou o argumento defendendo que as democracias se caracterizam por atributos que capacitam trabalhadores na medida em que incentiva a sindicalização, a negociação salarial centralizada e 
a existência de salários mínimos, o que reduz a desigualdade de rendimentos. Scheve e Stasavage (2009) mostraram que a densidade sindical (porcentagem de membros da população economicamente ativa que estão em sindicatos) e a concentração das negociações salariais estão negativamente correlacionadas com a desigualdade econômica.

Wallerstein (1999) analisa a desigualdade nos salários entre 16 economias avançadas e encontra fortes evidências de que a centralização do processo de negociação salarial é forte redutor das disparidades de rendimentos. Outros fatores importantes também são a própria concentração de poder dos sindicatos e a parcela da força de trabalho coberta por acordos de barganhas salariais coletivas. Para Wallerstein, a associação entre a centralização do processo de negociação salarial e uma distribuição mais equitativa de ganhos decorreria do fato que a centralização altera a influência de diferentes grupos no processo de definição salarial ao comprimir a estrutura dos salários e, assim, indiretamente, reduzir a desigualdade de ganhos. Ademais, se os trabalhadores mais produtivos optarem por sair do acordo central, o efeito da centralização será intensificado na calda final da distribuição de renda, afetando negativamente a desigualdade (WALLERSTEIN; GOLDEN; LANGE, 1997).

Rueda (2008) demonstra que o corporativismo é uma variável que afeta a capacidade dos partidos políticos em produzir políticas que reduzam a desigualdade, sobretudo no que toca à variação salarial. De acordo com o autor, em sistemas corporativos os partidos políticos não possuem graus de liberdade para afetar a desigualdade salarial. Apenas nos países cujo nível de coordenação na barganha entre empregadores e empregado é baixa é que a política partidária consegue afetar a desigualdade econômica por meio do estabelecimento de sa- 
lários mínimos maiores, gastos do governo com o estado de bem-estar social e no financiamento do estado por meio de impostos sobre o trabalho.

Finalmente, vale a pena mencionar como último ponto as relações teóricas entre democracia e desigualdade. Alguns autores propõem que esta relação não é encontrada em curto, mas sim em longo prazo. As estruturas institucionais de maior dispersão do poder político nas democracias demoram para afetar as estruturas de concentração - difusão dos recursos econômicos. Deste modo, apenas ao longo de uma extensa trajetória democrática que a desigualdade econômica entre os cidadãos tende a ser arrefecida. Sirowy e Inkeles (1990) e Gradstein e Milanovic (2004) ao reverem a literatura empírica que trata sobre o tema concluem que os resultados mais robustos são aqueles que analisam o tamanho da experiência democrática com a desigualdade econômica. Muller (1988) reporta que aproximadamente 20 anos de experiência democrática são necessários para os efeitos igualitários da distribuição do poder político atingirem e arrefecerem a concentração do poder econômico ${ }^{13}$.

\subsection{Resultados empíricos}

Apesar desse já extenso e já bem desenvolvido arcabouço teórico que integra ao regime político democrático uma

\footnotetext{
13 Ainda que não estejam preocupados na análise entre a relação da democracia com a desigualdade econômica e sim com os efeitos das instituições de trabalho, instituições eleitorais e da ideologia política dos partidos, o trabalho de Scheve e Stasavage (2009) deixa claro a importância de se analisar os efeitos de longo prazo das instituições sobre a desigualdade econômica, uma vez que em curto prazo as mudanças institucionais tendem a ser menores e a dinâmica da desigualdade tende a reagir lentamente aos eventos do mundo da política.
} 
dinâmica de redução de desigualdade econômica, os achados empíricos não são robustos e surpreendem o leitor. $\mathrm{Na}$ visão de Timmons (2010), este enorme descompasso existente entre as teorias que vislumbram um potencial democrático em reduzir as desigualdades econômicas e as evidências empíricas pode ser parcialmente atribuído à escassez de dados confiáveis sobre a mensuração da desigualdade econômica ${ }^{14}$, sem contar os enormes problemas conceituais relacionados à que tipo de desigualdade econômica a democracia opera para reduzir: a desigualdade de consumo, a desigualdade de ganhos ou mesmo a desigualdade da capacidade de se obter renda econômica.

Em uma extensa revisão dos primeiros esforços da literatura quantitativa em estimar o efeito da democracia sobre a desigualdade, Sirowy e Inkeles (1990) analisaram doze diferentes estudos. Entre estes, sete estudos ${ }^{15}$ acharam efeitos da democracia em direção à redução da desigualdade econômica, enquanto outros cinco ${ }^{16}$ mostraram que esses efeitos são positivos, porém estatisticamente insignificantes. Contudo, alguns achados devem ser qualificados. Em Cutright (1967) os efeitos são encontrados apenas nas economias médias e pobres, enquanto não há efeitos entre as economias mais ricas. Hewitt (1977), por sua vez, argumenta que os efeitos do regime político democrático são de fato efeitos espúrios e causados primordialmente pelas sociais democracias. Por fim, Muller (1988)

\footnotetext{
14 No capítulo 3 apresentamos de maneira mais detalhada as dificuldades e soluções para a mensuração do fenômeno da desigualdade econômica.

15 Cutright (1967); Hewitt (1977); Stack (1979; 1980); Weede e Tiefenbach (1981); Weede (1982); Muller (1988).

16 Jackman (1975); Rubinson e Quinlan (1977); Bollen e Grandjean (1981); Kohli et al. (1984); Bollen e Jackman (1985).
} 
encontra evidências de que é a extensão da experiência democrática e não o nível de democracia que reduz a desigualdade.

Por sua vez, Rubinson e Quinlan (1977) controlam as estimações para o problema da causalidade reversa usando um sistema de equações da múltipla relação entre democracia e desigualdade e encontram um efeito da desigualdade sobre a democracia, mas não da democracia sobre a desigualdade. Já Bollen e Jackman (1985) reexaminam a análise de Rubinson e Quinlan e não encontram efeitos significantes em nenhuma das direções causais. Assim, Sirowy e Inkeles concluíram que é ambígua a evidência de que a democracia reduz a desigualdade econômica, ainda que a medida da extensão da experiência democrática parece contribuir mais diretamente com a equalização das relações econômicas.

Resultados mais otimistas, ainda que cautelosos, foram encontrados na revisão da literatura elaborada por Gradstein e Milanovic (2004). A revisão levantou alguns estudos históricos que encontraram forte associação entre a extensão do sufrágio, sobretudo o direito de voto às mulheres, com um aumento do gasto público redistributivo nos EUA, Inglaterra e Suíça, (HUSTED e KENNY, 1997; ABRAMS; SETTLE, 1999; JUSTMAN; GRADSTEIN, 1999; LOTT JR; KENNY, 1999), enquanto Mueller e Stratmann (2003) encontraram evidências de que quanto maior o turnout eleitoral, maior é a redução da desigualdade.

Assim como Bollen e Jackman (1985), Gasiorowski (1997) e Lundberg e Squire (1999) reportaram que os efeitos da democracia sobre a desigualdade econômica são estatisticamente insignificantes ${ }^{17}$, enquanto Muller (1988), Moon

${ }_{17}$ Lundberg e Squire (1999) encontraram um efeito protetor da democracia em 
(1991) e Rodrik (1998a) sustentaram que a democracia de fato reduz a desigualdade, ainda que os potenciais mecanismos causais fossem distintos. Chan (1997), por sua vez, reportou resultados mistos, analisando os efeitos da democracia sobre diferentes tipos de gastos públicos redistributivos ${ }^{18}$, enquanto Simpson (1990) e Justman e Gradstein (1999) argumentaram, utilizando uma mensuração contínua de democracia, que a desigualdade de renda aumenta com a democracia até certo nível de democracia, após o qual os efeitos começam a declinar, numa espécie de curva política de Kuznets. Por fim, Nielsen e Anderson (1995) também propuseram uma relação num formato $\mathrm{U}$-invertido, mesmo que seus achados não se mostrem robustos à inclusão de novos controles.

Um dos principais problemas enfrentados nesses estudos é a escassez de dados, o que impede a obtenção de conclusões confiáveis. Boa parte dos testes usou dados de cortes transversais, o que impede o controle para efeitos temporais dinâmicos ou mesmo efeitos que se diferenciam ao longo do tempo em cada país. Um passo mais consistente foi dado com a publicação da compilação de dados sobre desigualdade feita por Klaus Deininger e Lyn Squire, patrocinada pelo Banco Mundial, que deu origem ao primeiro banco de dados em painel sobre a desigualdade econômica (DEININGER; SQUIRE, 1996). Os estudos empíricos que fizeram uso do Banco de dados

relação ao último quintil da distribuição de renda, impactando, portanto, na redução da pobreza. Ademais, este paper foi o primeiro a incluir uma amostra com vários casos de países pós-comunistas do leste europeu.

18 Comparando os gastos públicos de Taiwan, Coréia do Sul e Cingapura, Chan (1997) concluiu que os gastos em educação e previdência social aumentaram depois da democratização de Taiwan e Coréia do Sul, enquanto na Coréia do Sul também houve crescimento nos gastos com habitação. Por outro lado, o autor não encontrou efeitos da democracia sobre os gastos em saúde. 
de Deininger e Squire (DS) concluíram de maneira mais consistente que mais democracia resulta em menos desigualdade.

Li, Squire e Zou (1998); Chong (2004) e Reuveny e Li (2003) usaram o DS e encontraram uma relação negativa entre democracia e desigualdade. Li, Squire e Zou (1998) mostraram que o nível de liberdades civis, mensurado com os indicadores da Freedom House, e os níveis de escolarização secundária, mais uma medida de abrangência do sistema financeiro e a distribuição inicial de terras são determinantes importantes do nível de desigualdade. Na visão dos autores, as duas primeiras variáveis medem constrangimentos que as elites econômicas e políticas enfrentam para influenciar as políticas públicas e as duas últimas medem fatores estruturais econômicos que moldam o acesso dos pobres ao mercado financeiro. Outro importante achado da pesquisa de Li, Squire e Zou é que a maior parte da variância dos coeficientes de GINI é decorrente de um corte transversal (65\%) e não temporal. Mudanças na desigualdade foram muito lentas na maioria dos países, sugerindo que fatores estruturais possuem um papel fundamental na determinação do nível de desigualdade e tornam muito difíceis transformações profundas em curtos períodos de tempo.

Chong (2004) também ofereceu evidências sobre a conexão entre democracia e desigualdade econômica no período de 1960-1995. Em uma regressão transversal, usando médias amostrais para o período e também painéis dinâmicos, o autor encontrou uma relação não monotônica entre democracia e desigualdade, sustentando mais uma vez a possível existência de uma curva de Kuznets política. O conjunto de variáveis controles consistia do PIB per capita inicial, indicadores de saúde (número de médicos por habitante), participação de agricultura e da indústria na economia e a taxa de inflação. 
Reuveny e Li (2003), por sua vez, estudaram os efeitos da democracia levando em conta os efeitos da abertura econômica. Para estes autores, ambas as variáveis afetam a desigualdade, enquanto a abertura econômica também afeta a democracia (IM, 1996; WHITEHEAD, 1996; DRAKE, 1998; HELD, 1999).

Desta maneira, estudos empíricos que não as levem simultaneamente podem estimar resultados enviesados ao atribuir o efeito de uma à outra. Em sua análise empírica, Reuveny e Li dividem sua amostra por nível de desenvolvimento, testando sua teoria em países desenvolvidos, em países em desenvolvimento e numa terceira com todos os países. Como resultado, concluem que a democracia sempre reduz a desigualdade econômica, enquanto a abertura econômica só reduz a desigualdade nos países em desenvolvimento. Todas as variáveis nos modelos foram computadas como médias por décadas

Do outro lado da moeda, Timmons (2010) replicou a análise de Li, Squire e Zou (1998), Chong (2004), e Reuveny e Li (2003) usando novos e mais robustos dados The World Income Distribution Database - WIID (2007) ${ }^{19}$, o sucessor do DS, e não encontrou resultados que indicassem algum impacto significante da democracia na desigualdade econômica. Usando em sua análise dados agregados em médias por décadas e por quinquênios, Timmons não encontrou nenhuma relação entre democracia e liberdades civis com as medidas de desigualdade econômica. Sua alegação final é que a questão sobre

19 UNU-WIDER (Unu/Wider-Undp) (World Institute for Development Economics Research), World Income Database (WIID), Versão 2 (Helsinki: World Institute for Development Economics Research of the United Nations University/UNDP, May 2007). O banco de dados de Deininger e Squire (DS) contém 2634 observações contra 4982 do WIID (Timmons, 2010). Uma discussão aprofundada sobre os diferentes bancos de dado comparados de GINI é apresentada no capítulo 3 . 
os efeitos da democracia sobre a desigualdade econômica ainda permanece aberta, mas que os novos bancos que compilam dados de natureza longitudinal prometem revolucionar o campo de pesquisa da relação entre desigualdade e democracia.

Alguns estudos realizados no último decênio também desafiaram esse suposto consenso teórico sobre os efeitos dos regimes políticos em relação a outras medidas de desenvolvimento humano. Por exemplo, os estudos de Gauri e Khaleghian (2002) McGuire (2006), Ross (2006) e Shandra, Nobles, London e Williamson (2004) não encontraram correlações positivas e robustas entre indicadores de desenvolvimento humano e a presença de um regime político democrático (GERRING; THACKER; ALFARO, 2012) ${ }^{20}$.

\subsection{Desenvolvimento, choques tecnológicos e desigualdade}

Na análise da relação entre democracia e desigualdade é necessário estarmos atentos para o fato de que existem outros fatores externos que interferem na relação. Por exemplo, uma extensa literatura discute como o desenvolvimento afeta a desigualdade, interagindo com os próprios efeitos da democracia (KUZNETS, 1955). Somando esta discussão à literatura que analisa a associação entre desenvolvimento e democracia, torna-se claro a necessidade de se controlar o seu papel para a estimação dos reais efeitos da democracia sobre a desigualdade. Outros potenciais fatores de confusão descritos nos próximos parágrafos decorrem do papel interveniente dos mercados na

\footnotetext{
${ }^{20}$ Gauri e Khaleghian (2002) tomaram como variável dependente a cobertura de vacinação da população e Ross (2006), MacGuire (2006) e Shandra, Nobles, London e Williamson (2004) a taxa de mortalidade infantil.
} 
relação entre democracia e desigualdade. Posto isso, apresentamos de maneira bastante sucinta as vertentes da literatura que analisam a relação entre desenvolvimento, mercados, globalização e desigualdade. A metodologia e os dados empíricos serão detalhados nos próximos capítulos.

A análise da relação entre desenvolvimento e desigualdade data da contribuição seminal de Simon Kuznets (1955) na qual o autor defende a hipótese de que durante o processo de desenvolvimento econômico e transformação de uma sociedade rural e agrária em uma sociedade industrial urbana, a desigualdade segue um padrão de $\mathrm{U}$-invertido, com um inicial aumento e posterior queda. A curva de Kuznets se assemelha a uma parábola com concavidade para baixo. Antes do processo de industrialização na Inglaterra e nos Estados Unidos, a atividade econômica principal consistia basicamente em conjunto de pequenos proprietários familiares, cuja renda da atividade agrícola era limitada pelo escopo natural do trabalho familiar. A partir do surgimento de uma vida urbana mais dinâmica nos estágios iniciais da industrialização, a desigualdade tenderia a aumentar. Isso acontecia porque nessa fase ocorria um aumento da demanda por mão de obra nos setores mais modernos da cidade, elevando os salários dos trabalhadores urbanos em detrimento dos que permaneciam na zona rural.

Com o passar do tempo, a migração e, por fim, a industrialização da agricultura deslocou os trabalhadores rurais para a cidade. A população rural declinou, assim como a importância do diferencial de renda entre o campo e a cidade e a desigualdade passou a ser reduzida com o crescimento da renda, sobretudo pelo fato que a população se deslocou do campo, tornando-se urbana. Apesar do fato de que as cidades fossem ambientes econômicos mais diversos que o campo, e naturalmente mais 
desiguais, Kuznets tinha a expectativa de que com a maturidade da industrialização, a sindicalização dos trabalhadores e o avanço da social democracia haveria redução ainda mais forte da desigualdade. Assim, a desigualdade como um todo deveria declinar com o aprofundamento do desenvolvimento industrial na medida em que o desenvolvimento econômico urbano progredisse (GALBRAITH, 2012).

A hipótese de Kuznets é motivada para analisar o processo de transição econômica estrutural e demográfica da modernização, mas a relação U-invertida pode surgir a partir de qualquer transição entre atividades com níveis distintos de produtividade. Isto porque com a transição de uma economia centrada em uma atividade de pouca produtividade para uma atividade de alta produtividade há um inevitável aumento da desigualdade durante o processo, em benefício da parcela da população que atua na atividade altamente produtiva. Com o passar do tempo e a transição de boa parte da população para esta atividade, os retornos voltam a ser equiparados.

Outro fator assemelhado à lógica do modelo de Kuznets são os efeitos das novas tecnologias, tal como proposto no modelo de Boix (2010) onde os choques exógenos afetam de maneira incisiva a distribuição de ganhos. $\mathrm{O}$ argumento de Kuznets seria apenas um caso especial no qual existe um choque tecnológico - a industrialização - em uma atividade que gera mais renda para determinado grupo da sociedade - a população urbana. Contudo, Boix incrementa o modelo com a possibilidade de criação de barreiras de entrada no novo mercado, premiando aqueles que foram beneficiados inicialmente com a alteração tecnológica ${ }^{21}$.

${ }^{21}$ Boix (2010) tem como objeto a evolução da desigualdade de longa duração.
O primeiro choque exógeno analisado é decorrente da revolução agrária - 
O papel da evolução da tecnologia é outro fator crucial na evolução da desigualdade. Na visão de Boix (2010), as evoluções tecnológicas se dividem, basicamente, entre dois extremos: pró-pobres e pró-elites. Um exemplo de choques pró-elites é a descobertas de recursos naturais ou o boom em preços de commodities, que aumentam a desigualdade ao beneficiar aqueles que controlam os recursos naturais de uma dada sociedade. Já um choque pró-pobres é aquele que aumenta mais a renda dos indivíduos pobres em relação à elite e cujos efeitos tendem a ser sufocados caso o eleitor decisivo na sociedade seja membro da elite econômica e não das massas.

Uma das explicações econômicas a respeito do exponencial crescimento da desigualdade econômica nas economias mais avançadas do mundo nos últimos 30 anos tem sido analisada como consequência de um choque econômico pós-revolução tecnocientífica e um decorrente aumento dos retornos da educação. Em revisão da literatura a respeito das causas e consequências da desigualdade, Neckerman e Torche (2007), analisando o caso americano, discutem os efeitos da computadorização do campo de trabalho sobre o aumento do valor de mercado da educação e de habilidades específicas para o uso da tecnologia.

Recentemente Autor, Katz e Kearney $(2005$; 2006) propuseram uma versão modificada do argumento tecnológico como fonte do aumento das desigualdades nas últimas décadas.

domesticação de plantas e animais. Os grupos beneficiados com esse choque econômico exógeno seriam aqueles que exerciam atividades agropastoris em terra mais férteis e produtivas. Com o advento da revolução agrária, esses indivíduos obtiveram mais renda do que aqueles que viviam na periferia das grandes planícies férteis. Tal processo desencadearia uma teia de relações econômicas e políticas que justificaria a formação do Estado e o surgimento de regimes políticos mais ou menos autoritários. 
A computadorização aumentaria a competitividade de profissionais altamente qualificados, reduzindo os retornos e a demanda por trabalho rotineiro, normalmente alocados para indivíduos com salários médios. Tais transformações tecnológicas teriam pouco efeito nos salários dos trabalhadores alocados no final da distribuição de renda. Fernandez (2001) inclusive sugere uma associação importante entre o aumento da dispersão salarial e a atualização tecnológica.

Para Galor e Tsiddon (1997) e Aghion e Howitt (1998), a tecnologia aumenta a concentração de trabalhadores qualificados nos setores mais avançados da economia em prejuízo dos trabalhadores menos qualificados, alocados em setores mais atrasados, aumentando a desigualdade de pagamentos. Galbraith (2012) encontra evidências de que o setor industrial é a atividade mais afetada pelas mudanças tecnológicas e a desigualdade induzida pela tecnologia possui características distintas entre diversos setores manufatureiros, tendo reflexo na distribuição dos pagamentos e aumentando a diferença entre os trabalhadores dos setores mais modernos em relação aos outros.

Por fim, Rogowski e MacRae (2008) elaboraram outro modelo a respeito de como as dotações de fatores de produção, o comércio e os choques tecnológicos afetariam as instituições democráticas por meio da alteração dos níveis de desigualdade econômica por, entre outras coisas, aumentar ou reduzir os salários do trabalho em relação ao capital ao afetar a produtividade marginal de ambos de formas diferentes. Entre as mudanças tecnológicas discutidas, Rogowski e MacRae analisam o papel da tecnologia militar sobre o aumento ou diminuição da desigualdade:

Caso alguma mudança tecnológica como a introdução de melhores táticas de infantaria aumente a produtividade 
marginal do trabalho na produção da força militar, o trabalho tornar-se-á mais valorizado em relação ao capital. A sua remuneração aumentará, seja em termos monetários ou políticos, diminuindo a desigualdade. Da mesma forma, qualquer mudança tecnológica que aumente a produtividade marginal relativa do capital aumentará a desigualdade. (ROGOWSKI; MACRAE, 2008, p. 359) ${ }^{22}$.

\subsection{Democracia, mercados e desigualdade econômica}

Outro tema candente no debate a respeito da evolução da desigualdade na segunda metade do século XX é o papel que a expansão das relações de mercado tem sobre este fenômeno. Conforme apontado por Przeworski (2010), o surgimento da democracia foi uma revolução no mundo da política e não uma revolução social, tal como esperado no século XIX. A equidade política entre os cidadãos não necessariamente significa que a igualdade será difundida para todos outros atributos socioeconômicos que caracterizam a existência humana.

Ademais, a democracia tornou-se, ao longo de sua consolidação no século XX, num sistema político observado em nações com diferentes graus de desigualdade econômica. Isso se torna ainda mais latente ao verificarmos que as democracias políticas funcionam na maioria dos casos em sistemas

\footnotetext{
${ }^{22}$ Exemplos históricos de choques exógenos que aumentaram a produtividade relativa do capital foram as legiões profissionais romanas, a cavalaria armada medieval e os exércitos modernos absolutistas. Já exemplos que aumentaram a produtividade relativa do trabalho foram as forças hoplitas da Grécia Antiga, a peste negra que ao reduzir a oferta de trabalho, reduziu a produtividade relativa do capital em relação ao trabalho ou mesmo a possibilidade de imigração na Europa do século XIX e a sociedade de fronteira dos Estados Unidos, Canadá e Austrália (ROGOWSKI; MACRAE, 2008).
} 
econômicos nos quais os recursos são distribuídos via forças de mercado e que existe uma tendência inequívoca das relações de mercado gerarem e reproduzirem desigualdade econômica ao longo do tempo (PIKETTY, 2014). Przeworski (2010) entende que nenhum sistema político organizado em uma sociedade de mercado pode gerar e manter uma perfeita equidade no campo socioeconômico.

$\mathrm{O}$ autor chama atenção para o fato de que além das dificuldades políticas da construção de qualquer mecanismo institucional de redistribuição de recursos, a própria linguagem da redistribuição é anacrônica, refletindo o conflito redistributivo sobre a posse e uso da terra, um bem divisível e manejável por unidades familiares. Nenhum outro insumo produtivo pode ser tão facilmente redistribuído como a terra. Muitas vezes existem barreiras tecnológicas que impedem a redistribuição de um tipo de ativo econômico, como, por exemplo, os insumos de indústrias tecnologicamente avançadas, ou mesmo a própria distribuição de capital humano, um bem não divisível e cujo domínio e expansão geram externalidades positivas muito difíceis de serem controladas via mercado ou mesmo via controle político.

Posto isto, Przeworski (2010) entende que a construção da cidadania igualitária dentro de sistemas políticos democráticos não implica em que as diferenciações sociais entre os cidadãos serão reduzidas, mas sim que o sistema político não observará as diferenças socioeconômicas entre os concidadãos. Assim, o cidadão democrático seria simplesmente o cidadão sem categorização e anônimo. Não sendo iguais e muito menos homogêneos, mas sim necessariamente anônimos perante as leis, as instituições e o próprio sistema político. Desta forma, a potencial tensão entre um sistema de equidade política 
e a produção e reprodução de desigualdades via relações de mercados tornar-se-ia tolerável do ponto de vista lógico, ainda que com consequências empíricas e políticas fundamentais ${ }^{23}$. A equidade política seria, assim, a equidade aos olhos do Estado e não nas relações diretas entre os cidadãos.

Por outro lado, é inevitável esperar que de alguma forma o advento da equidade política torne-se um mecanismo de redução das desigualdades econômicas, sobretudo em relação ao direito de propriedade, tal como já exposto na introdução deste capítulo. Contudo, para Przeworski (2010), independente de qual seja o formato institucional do governo, se não houver esforço político ativo e perseverante para a proteção dos mais pobres por meio de algum mecanismo de transferência de recursos para os indivíduos que possuem uma menor capacidade de obtenção de renda, a desigualdade tenderá a crescer em uma sociedade cuja economia é organizada via relações de mercado. A experiência neoliberal das últimas décadas exemplifica tal suposto, pois com a redução do papel do governo na economia dos países capitalistas houve profundo e rápido crescimento da desigualdade (PIKETTY, 2014).

Outra justificativa crucial para o controle dos fatores relativos ao fenômeno da expansão das relações de mercado decorre do fato de que com o fim da Guerra Fria e a terceira

\footnotetext{
${ }^{23}$ Przeworski (2011a) analisa o papel que as diferenças econômicas têm no curso normal da competição política e como uma distribuição de renda desequilibrada afeta a capacidade de influência dos indivíduos detentores de menos recursos. Na visão de Przeworski alguns cidadãos não podem equalizar o custo marginal da influência na política com os benefícios marginais decorrentes, pois sofrem constrangimentos orçamentários, o que, portanto, tem como consequência direta um viés político favorável aos cidadãos detentores dos recursos econômicos. Para uma discussão sobre os mecanismos pelos quais o dinheiro afeta a política vide (PRZEWORSKI, 2011a; 2012).
} 
onda da democratização (HUNTINGTON, 1993) ocorrem dois processos distintos, mas concomitantes: a expansão de regimes políticos democráticos e a expansão de processos econômicos liberalizantes em temas de comércio exterior e das próprias relações econômicas internas, denominado na literatura como onda neoliberal. Como esses dois processos ocorreram ao mesmo tempo é bastante provável que os reais efeitos da democracia sobre a desigualdade foram mitigados pelos efeitos das relações econômicas menos reguladas.

Do mero fato que um país se democratiza e apresenta dados crescentes de desigualdade não decorre que a democracia não seja uma força equalizadora da sociedade, mas sim que o resultado líquido da soma dos efeitos dos mercados e da democracia é positivo. Isto porque a partir da década de 1990, muitos países tornaram-se democracias, ao mesmo tempo em que optaram por agendas de políticas econômicas mais liberalizantes. Desta maneira, é de fundamental importância desagregar os efeitos sobre a desigualdade causados por relações de mercado dos efeitos causados pela competição eleitoral em eleições democráticas.

Os processos de democratização política e liberalização econômica, embora concomitantes, são independentes. A história chilena na segunda metade do século XX ilustra bem esse fato. Antes do golpe comandado pelo general Augusto Pinochet, o então presidente Salvador Allende, que havia sido eleito democraticamente, estava direcionando a política econômica chilena para um ponto distante de políticas voltadas à liberalização de mercado. E depois de 1973, o regime militar de Pinochet colocou o Chile no caminho da liberalização econômica em um momento em que não havia liberdade política. O golpe militar chileno é paradigmático para ilustrar como 
liberdade política e liberdade econômica podem estar separadas, uma vez que o oposto à liberdade política é autoritarismo, enquanto a antítese da liberdade econômica é o planejamento centralizado. Posto de outra forma, a liberdade política não é equivalente à liberdade de comprar, ainda que muitas vezes teóricos econômicos como Milton Friedman tenham feito essa associação equivocada (GALBRAITH, 2008). Nas palavras do economista James Galbraith:

Enquanto isso, o regime de mercado livre de Augusto Pinochet trouxe a liberdade econômica para o Chile. As pessoas podiam ser livres economicamente sem ter qualquer voz na política, enquanto viviam sob os coturnos de uma junta militar. (GALBRAITH, 2008, p. 16).

Argumentação semelhante é feita por Cardoso (2011) ao analisar o tema do debate político sobre o liberalismo no Brasil contemporâneo:

E como o liberalismo econômico leva à desigualdade, acabamos por não acreditar no liberalismo político, que é um valor. O liberalismo político é um valor que foi reivindicado pelos socialistas no século XIX, inclusive por Marx. A liberdade política como valor político é extremamente importante. A liberdade como laissez-faire econômico é inaceitável sem contrapesos. Um regime de liberalismo econômico não leva à igualdade e nem, no limite, à liberdade política. Mas há confusão entre esses termos. (CARDOSO, 2011, p.58).

Por fim, é de fundamental importância analisar se e $o$ quanto a expansão das relações de mercado podem afetar a desigualdade econômica, tal como esperado por Przeworski, Pikkety e Galbraith. Há vasta discussão sociológica e econômica 
que data desde as contribuições de pensadores do século XIX como Karl Marx, passando pela obra de Karl Polanyi (1957; 2013), de que a economia de mercado, ao ser guiada pela busca e expansão dos lucros, tende a reduzir a participação do trabalho nos ganhos, tratando-a necessariamente como uma entre outras simples commodities e aumentando, assim, a distância entre ricos e pobres.

Outras abordagens como a teoria da dependência (CARDOSO E FALLETO, 1970; EVANS, 1979) e Evans (1979) e a teoria das vantagens cumulativas de (MERTON, 1973) indicam também que em uma economia de mercado os ricos expandem a sua renda a uma taxa maior do que os pobres, aumentando a sua vantagem relativa. Um possível mecanismo por detrás do fenômeno da expansão dos mercados é que o poder de barganha do trabalho é limitado quando a propriedade dos meios de produção encontra-se na mão de um grupo reduzido de indivíduos, os capitalistas.

Estudo de Szelenyi e Manchin (1987) sobre a expansão das relações de mercado na Hungria indica, outrossim, que a liberalização teve como consequência principal a pauperização real dos que ocupam as menores faixas da distribuição de renda. Outros trabalhos que focaram a emergência da economia de mercado no Leste Europeu também endossam a visão de que os mercados ampliam a desigualdade econômica, prejudicando os mais pobres e beneficiando um pequeno grupo de privilegiados (HANKISS, 1990a; b; STANISZKIS, 1991; RONA-TAS, 1994).

O mesmo padrão se repete na China, onde, seguindo os padrões teorizados por Simon Kuznets, há uma enorme diferenciação dos ganhos no campo em relação aos ganhos do setor urbano, centro do dinamismo econômico chinês após a introdução e avanço das reformas econômicas modernizantes 
e orientadas para o mercado de Deng Xiaoping (ZHAO, 1993). Os efeitos de ampliação da desigualdade decorrentes da expansão das relações de livre mercado são ainda mais fortes quando os indivíduos que se veem livres para competir por remuneração e renda possuem diferentes estoques de capital humano e/ou diferentes conjuntos de talentos e habilidades (NEE; LIEDKA, 1997).

Diante de tais constatações, Przeworski (2012) tenta enunciar uma "Lei Newtoniana" da desigualdade, na qual a desigualdade de renda tende a crescer como resultado da operação dos mercados quando o governo não atua ativamente para contrabalancear e frear tal tendência. Fora isso, a tendência ao crescimento e manutenção da desigualdade de mercados simplesmente persiste e tende a ser reduzida de forma aguda somente na presença de eventos catastróficos como revoluções sociais (União Soviética), intervenções militares externas (papel japonês na Coréia ou soviético no Leste Europeu), guerras ou emigração maciça dos pobres (Noruega e Suécia) ou mesmo o próprio efeito da $1^{\text {a }}$ e $2^{\text {a }}$ Guerra Mundial como indutor da redução da desigualdade salarial nos EUA e na Europa Ocidental (GOLDIN; MARGO, 1992), (SCHEVE; STASAVAGE, 2009) e (PRZEWORSKI, 2012) ${ }^{24}$.

${ }^{24}$ Piketty (2014), Piketty e Saez (2003; 2006) e Moriguchi e Saez (2008) demonstram que países como França, Reino Unido, EUA e Japão assistiram a uma forte redução da desigualdade durante a $1^{\text {a }}$ e a $2^{\text {a }}$ Guerra Mundial que deve ser atribuída a uma queda drástica da renda do capital do topo da distribuição de renda, uma vez que fortunas foram reduzidas como resultado da inflação em tempos de guerra e da própria taxação para o esforço militar, associados à introdução do imposto de renda progressivo. 


\subsection{Globalização e comércio internacional}

Como a expansão das economias de mercado é um processo complementado pelo aprofundamento da globalização, estando ambos associados temporalmente à própria expansão da democracia pelo mundo, é necessário separar as contribuições de cada um destes três fatores sobre a desigualdade econômica. Podemos considerar a democratização, a liberalização econômica e a globalização como o tripé fundamental da nova ordem internacional e, portanto, que constituem fenômenos nitidamente inter-relacionados. Isto porque o exponencial crescimento das relações de mercado no último quartel do século XX estimulou de maneira inequívoca a aceleração do processo de globalização. A própria expansão dos mercados ocorre concomitantemente à democratização das relações políticas dentro das nações, embora a aproximação entre mercado e democracia seja mais tensa que a afinidade entre mercados e globalização.

Frankel (2000) entende a globalização econômica como uma das forças mais poderosas que moldaram o mundo no pós-guerra. Em particular, o comércio internacional de bens e serviços, que se tornou cada vez mais importante ao longo dos últimos 60 anos e os fluxos financeiros nos últimos 40 anos. Em sua opinião, os vetores do processo de globalização econômica são os avanços tecnológicos que permitiram a redução dos custos de transportes e comunicações na atuação do setor privado e a redução das barreiras sobre os fluxos comerciais e financeiros por parte do setor público.

A literatura comparada ainda não produziu conclusões consensuais a respeito do que seja a globalização e mesmo de quais são os efeitos da própria expansão das economias de 
mercado sobre o agravamento ou não da desigualdade econômica. Nas palavras de Brune e Garret (2005), o debate sobre os efeitos da globalização econômica sobre a desigualdade assemelha-se a um gigante teste de Rorschach: os analistas observam o mesmo tipo de informação, mas tendem a tomar conclusões diferentes e normalmente enviesadas ideologicamente.

O consenso não emergiu entre outras coisas, pois a própria definição do que signifique o constructo globalização ainda não é consensual. Em consequência, as propostas de mensuração empírica do construto são bastante contestáveis, pois tendem a simplificar o complexo fenômeno em termos de integração de mercado de bens, serviços ou de capitais. Por exemplo, alguns pesquisadores mensuram o quanto um país é integrado ao mercado global por meio da análise de fluxos de comércio ou de capital (RODRIK, 1998a; b), (DOLLAR; KRAAY, 2001) e (MILANOVIC, 2003; 2005) ou por meio da análise de medidas de política econômica, como, por exemplo, níveis tarifários e abertura do mercado de capitais (QUINN, 1997), (GARRETT, 1998a), (BIRDSALL; HAMOUDI, 2002), (SWANK, 2003), (BRUNE; GARRETT; KOGUT, 2004) e (GARRETT, 2004).

Ademais, outros fatores de confusão do próprio processo de expansão da globalização precisam ser integrados à análise. Os acordos de livre comércio e o próprio processo de integração econômica e política regional, como, por exemplo, o MERCOSUL e a UNIÃO EUROPÉIA (UE), possuem efeitos sobre a velocidade da integração econômica e sobre a própria distribuição de bens entre os indivíduos (BECKFIELD, 2006; 2009) e (PASTOR; SERRANO, 2012). Beckfield (2009), por exemplo, apresenta dados em que, de um lado a integração europeia reduziu a diferença entre países e do outro aumentou 
a desigualdade dentro de cada país. Os acordos regionais não apenas criam comércio e fomentam investimentos dentro da região, mas também afetam a distribuição de recursos nos países membros da união como desviam comércio e investimentos que seriam realizados em países que estão fora do acordo.

É bastante razoável assumir a hipótese de que os efeitos da globalização em sociedades muito desiguais sejam distintos dos efeitos em sociedades que já possuem uma cesta de bens distribuídos de maneira mais uniforme. $\mathrm{O}$ modelo de Heckscher-Ohlin (HO), por exemplo, prevê, adaptando-o à economia contemporânea globalizada, que o surgimento de um mercado comum global afeta de maneira distinta os países nos quais o trabalho qualificado é abundante daqueles onde há mais trabalhadores dotados de poucas habilidades (BRUNE; GARRETT, 2005; MESCHI; VIVARELLI, 2009). A intuição é simples: com a redução das barreiras contra a livre circulação de bens e investimentos, os salários relativos dos trabalhadores nos setores com vantagens comparativas devem subir. E nos países mais desiguais as vantagens comparativas estariam concentradas nas atividades das quais participam os trabalhadores menos qualificados, enquanto nos países mais iguais, as vantagens residem nas atividades das quais participam os trabalhadores mais qualificados (BEYER; ROJAS; VERGARA, 1999).

Em outro enfoque abordado por Boix (2011) existe uma discussão importante a respeito dos efeitos da globalização econômica do ponto de vista da oferta e da demanda por redistribuição. Em relação ao primeiro, a oferta de redistribuição deve diminuir, pois a capacidade dos estados perseguirem políticas econômicas autônomas dentro de seu próprio país é prejudicada pela integração global, uma vez que se veem constantemente ameaçadas pela possibilidade dos fatores de 
produção, sobretudo o capital, migrarem para outros países na presença de políticas que afetem suas respectivas margens de lucro, como, por exemplo, uma política que aumenta a transferência de renda da elite para segmentos menos favorecidos da sociedade ${ }^{25}$.

Wood (1994) atribuiu o crescimento da desigualdade nos últimos quarenta anos nas economias mais desenvolvidas ao resultado da globalização e à crescente competição com as economias em desenvolvimento, que possuem vantagens comparativas na produção de bens trabalho-intensivo, o que resulta numa redução dos salários dos trabalhadores pouco e semiqualificados nas economias mais avançadas. Autor (2010) e Spence e Hlatshwayo (2012) mostraram que o processo de globalização está associado a uma crescente polarização do emprego e salário entre os setores econômicos da América do Norte e Europa.

Por outro lado, do ponto de vista da demanda por redistribuição, quanto maior for o efeito da globalização sobre o aumento da desigualdade econômica, maior será a demanda por políticas redistributivas e por taxações que compensem os perdedores nacionais do jogo econômico global. Cameron (1978) observou que o melhor preditor do tamanho do setor público (fração do PIB) entre o período de 1960-1975 é o grau de abertura econômica, mensurado pela soma das exportações e importações sobre o próprio PIB. O mesmo foi encontrado

\footnotetext{
25 Em um dos modelos formais em Boix (2011), a globalização da economia nacional restringe os graus de liberdade do governo na elaboração de políticas redistributivas, ao reduzir a margem de imposto possível de ser aplicado. Ao se considerar que a mobilidade internacional dos ativos importa é esperado que o orçamento público se baseie mais nos setores específicos, como o próprio trabalho, do que nos menos específicos, como o capital. Isto porque esse último é mais apto a deslocar-se dentro da economia globalizada que o primeiro.
} 
por Rodrik (1996), que mostrou que quanto maior o risco externo decorrente das flutuações econômicas internacionais, maior é o setor público, uma vez que o emprego e a renda derivada deste setor não se correlacionam com choques externos de curto prazo.

Garret (1998b) também associa o tamanho do setor público com a abertura comercial, enquanto Mares (2005) encontra uma associação entre a introdução de esquemas de proteção social em decorrência da maior abertura. Adserà $\mathrm{e}$ Boix (2002) desenvolvem o argumento de que a abertura comercial só ocorre se os beneficiários oferecem compensações aos perdedores. Boix (2011) relata como a abertura comercial esteve associada à introdução de mecanismos de compensação no Reino Unido, Escandinávia, Austrália e Nova Zelândia entre 1830 e 1950 e na Europa do Sul entre 1930 e 1980. Por fim, Avelino, Brown e Hunter (2005) mostram que uma maior abertura econômica se correlaciona com maiores gastos sociais e educação na América Latina entre 1980 e 1999.

Boix (2011) inclusive aponta que este descompasso entre os efeitos da globalização sobre a demanda e oferta de redistribuição está nas raízes do descontentamento que certos setores da sociedade têm em relação ao mundo globalizado. O descontentamento de certos grupos decorre da percepção dupla de que a globalização impõe custos sociais e ao mesmo tempo reduz a capacidade de ação dos governos nacionais gastar tal como os cidadãos, no caso o eleitor mediano, preferem, pois limitam os graus de liberdade de taxar, tornando pior o bem-estar daqueles que perdem com a integração econômica.

Hobsbawn (2007) aponta os efeitos negativos da globalização em termos da expansão da desigualdade econômica da seguinte forma, inclusive trazendo potenciais repercussões políticas danosas para estabilidade dos regimes políticos: 
A globalização acompanhada de mercados livres, atualmente tão em voga, trouxe consigo uma dramática acentuação das desigualdades econômicas e sociais no interior das nações e entre elas. Não há indícios de que essa polarização não esteja prosseguindo dentro dos países, apesar de uma diminuição geral da pobreza extrema. Este surto de desigualdade, especialmente em condições de extrema instabilidade econômica, como as que se criaram com os mercados livres globais na década de 1990, está na base das importantes tensões sociais e políticas do novo século. (HOBSBAWN, 2007, p. 11).

Posto tal debate bastante polarizado e pouco consensual sobre as relações das três variáveis de interesse: mercados, democracia e globalização; apontamos a necessidade de se controlar os efeitos que a economia de mercado e a expansão da globalização econômica têm na relação entre democracia e desigualdade. Assim, no próximo capítulo apresentamos a abordagem com a qual tentamos eliminar as relações de confusão que as variáveis de mercado e globalização impõem à capacidade da democracia em reduzir a desigualdade econômica dentro de uma determinada sociedade.

\subsection{Causalidade reversa: os efeitos da desigualdade sobre os processos de democratização}

O último problema teórico a ser tratado neste capítulo decorre da existência de uma vasta literatura que busca analisar os efeitos da desigualdade como determinante dos processos de democratização. Nessa literatura a desigualdade é tratada como um entrave à possibilidade de um país tornar-se democrático, uma vez que quanto mais desigual for o país, 
mais a elite econômica tem a perder com a adoção do sufrágio universal em eleições competitivas nas quais as massas podem atuar livremente.

Nessas circunstâncias as sociedades com um alto grau de desigualdade não seriam um terreno fértil para a democracia. Modelos teóricos elaborados por Carles Boix (2003) e Acemoglu e Robinson (2006) tomaram como base o modelo de Meltzer e Richard e propuseram que o aumento da desigualdade tende a reduzir a probabilidade de uma ditadura transitar para um sistema democrático. Isto porque a ameaça de redistribuição de riqueza com a adoção do voto majoritário livre e a transferência do poder para as massas estimula a adoção de soluções antidemocráticas pelas elites política e econômica, que temem a expropriação de suas riquezas.

A lógica formal teórica da relação entre renda média e a renda mediana do modelo redistributivo de Meltzer e Richard é a mesma aplicada nos estudos sobre a transição democrática, que frequentemente enquadram as transições entre democracia e ditadura como uma disputa redistributiva (BOIX, 2003), (ACEMOGLU; ROBINSON, 2006) e (HOULE, 2009). Estas abordagens atualizaram os estudos de Barrington Moore (1966) e Rueschemeyer, Stephens e Stephens (1992) ao modelarem as formas nas quais as receitas do governo interagem com as demandas da sociedade e como o estado democrático pode servir como um compromisso crível com a redistribuição no futuro.

Boix (2003) propõe uma relação linear negativa entre desigualdade e democratização: quanto mais desigual for um país, menor será a probabilidade de ocorrer uma transição democrática. Os efeitos da desigualdade só são atenuados quando parte da riqueza da elite se encontra em tipos de capital que não são fixos (como, por exemplo, capital financeiro), uma 
vez que a flexibilidade de movimentação possibilita à elite econômica uma rota de fuga caso o poder político deseje extrair parte de sua propriedade. Assim, o cenário no qual a democratização é menos provável é justamente aquele no qual existe uma grande desigualdade econômica e a riqueza da elite é baseada em um capital fixo, como terra, que pode ser facilmente taxado e extraído pelo poder político.

Por sua vez Acemoglu e Robinson (2006) propõem que existe uma curva em formato de U-invertido entre desigualdade e probabilidade de democratização. Nas sociedades mais iguais as camadas populares não demandam maiores direitos políticos, pois a distribuição de recursos é equitativa e a obtenção do poder político não melhorará o bem-estar dos desfavorecidos e assim a probabilidade de democratização é baixa. Por outro lado, nas sociedades mais desiguais, ainda que exista uma forte demanda por redistribuição pelas camadas mais pobres, os custos da tolerância política da elite em relação à maioria pobre são muito altos e uma solução autoritária e repressora emerge. Por fim, apenas nas sociedades medianamente desiguais há uma maior probabilidade de democratização, uma vez que os custos de repressão são maiores que os custos da redistribuição e, além do mais, as massas possuem incentivos suficientes para se mobilizarem e organizarem. Assim, quando o problema de ação coletiva das massas for superado, a elite política e econômica responde às demandas por redistribuição econômica com a transferência do poder político para as massas.

O ponto fundamental do argumento de Boix e Acemoglu e Robinson é de que apenas com a efetiva transferência de poder da elite para as massas é que a redistribuição demandada tornar-se-ia crível. Mais uma vez, tal como na literatura 
que analisa os efeitos da democracia sobre a redistribuição, é feito um silogismo perfeito entre a igual distribuição de direitos políticos e a igual distribuição de recursos econômicos. Por outro lado, ainda que do ponto de vista teórico exista uma provável endogenia na relação entre democracia e desigualdade, do ponto de vista empírico a hipótese sobre quais são os efeitos da democracia sobre a desigualdade ainda é disputada. Adotando diferentes abordagens Houle (2009) não encontra uma associação clara entre desigualdade e democratização política, ainda que encontre uma relação entre igualdade e consolidação democrática. Já Ansell e Samuels (2010 e 2014) apresentam uma contraposição teórica na qual o aumento da desigualdade econômica está associado ao surgimento de uma classe média e, portanto, tende a aumentar a probabilidade de democratização de uma dada sociedade, invertendo completamente o modelo redistributivista de Meltzer e Richard.

O trabalho de Ansell e Samuels (2010 e 2014) parte de uma constatação empírica poderosa. Enquanto a desigualdade na Inglaterra no século XIX tinha um GINI de 0.51, a desigualdade na China era de 0.24 e, como sabido, a probabilidade de surgimento de um regime democrático era maior no primeiro caso. Essa ponderação decorre do fato que as novas classes que surgem no processo de modernização econômica (a burguesia e a classe trabalhadora) possuem uma renda superior à renda do eleitor mediano. Desta forma, o surgimento dessas novas classes que demandam por proteção contra a autoridade despótica do governo está associado a um aumento da desigualdade econômica e não a um aumento da igualdade.

Assim, Ansell e Samuels reveem as suposições teóricas do modelo redistributivo e colocam como questão chave no processo de democratização o medo de expropriação por 
parte da burguesia que surge a partir da modernização econômica contra os poderes absolutistas do Estado. Isto porque o aumento do coeficiente de GINI em países em desenvolvimento reflete o surgimento de uma classe média, mesmo que a maioria da população ainda permaneça na pobreza. Desta forma, o potencial eleitor mediano em sociedades em desenvolvimento é sempre um membro da classe mais empobrecida e que não participa e nem tem voz no mundo da política, colocando em questão todos os modelos redistributivos que fazem suas previsões a partir da preferência por redistribuição do eleitor mediano em situação autoritária.

Desta forma, o processo de democratização não se daria por intermédio da lógica da redistribuição, mas sim a partir da criação de uma classe média (composta pela burguesia e/ou a classe trabalhadora), que exigiria proteção contra as arbitrariedades do poder autocrático. Portanto, a ameaça fundante da democracia não foi a ameaça de redistribuição, mas sim a ameaça de extração. A democratização não foi sobre redistribuição, mas sim sobre taxação sem representação: um conflito entre elites econômicas rivais sobre o controle da autoridade coercitiva e expropriativa do Estado. O fundamento da democracia seria, portanto, o temor à ameaça à liberdade e à propriedade e não o ideal de transformação do poder político em igualdade econômica (ANSELL; SAMUELS, 2010; 2014).

\section{$\mathscr{8}$}

Neste capítulo apresentamos uma pequena amostra da vasta literatura que trata do tema da desigualdade econômica e de algumas das polêmicas que envolvem o debate. A longa lista de estudos demonstra a importância do tema na economia 
política comparada e como a discussão sobre a relação entre democracia e igualdade econômica é vasta e controversa. Nas primeiras seções apresentamos como a democracia é tratada na literatura da ciência social como um mecanismo de redução de disparidades econômicas, assumindo quase que um silogismo de que a igualdade política tem como consequência inevitável a igualdade econômica. Nas seções seguintes apresentamos novos problemas teóricos que mostram que a associação entre igualdade política e igualdade econômica não pode ser feita de maneira tão direta e inequívoca.

A presença de uma associação empírica entre liberdade política e liberdade econômica introduz ao problema uma série de dificuldades para que quaisquer tipos de sistemas políticos democráticos produzam a tão esperada igualdade econômica, uma vez que a existência de um sistema de trocas institucionalizado a partir de relações de mercado tem como consequência principal a criação de desigualdades. Problemas que se tornam ainda mais complexos com a globalização das relações políticas e econômicas e com os efeitos dos diferentes choques tecnológicos, que em algumas vezes melhoram a situação do trabalho, vis-à-vis do capital, e em outras vezes têm como consequência uma aceleração dos processos fomentadores de desigualdade.

Por fim, apresentamos a literatura que analisa a relação inversa ao interesse desta pesquisa. Existe importante, ainda que recente discussão sobre os efeitos da desigualdade econômica no processo de democratização em sociedades autoritárias, embora não seja possível assumir com clareza quais são os verdadeiros efeitos do crescimento da desigualdade para a inauguração e consolidação de democracias, uma vez que os achados de Ansell e Samuels (2010; 2014) vão na 
contramão do modelo redistributivo de Boix (2003) e Acemoglu e Robinson (2006).

Com efeito, no próximo capítulo apresentamos uma nova proposta teórica a respeito da relação entre democracia e desigualdade, de forma a mediar os efeitos do debate sobre a desigualdade entre outras dimensões que também importam no mundo da política, tal como desenvolvimento, crescimento, etnicidade e outras clivagens políticas. Em seguida, introduzimos a metodologia de pesquisa que busca investigar os diferentes problemas levantados nesse capítulo e na seção teórica do próximo. Por fim, no terceiro capítulo, finalizamos a introdução do problema ao apresentarmos quais são os requisitos, conceitos e critérios utilizados para mensurar o sistema político e o tamanho da desigualdade econômica de determinado país em determinado ano. 